Société d'histoire de la révolution de 1848 et des

révolutions du XIXe siècle

$46 \mid 2013$

L'espace du politique en Allemagne au XIX' ${ }^{\mathrm{e}}$ siècle

\title{
Claudine Hérody-Pierre, Robert Schnerb, un historien dans le siècle (1900-1962). Une vie autour d'une thèse
}

Collection Inter-National, Paris, L'Harmattan, 2011, 292 p. ISBN :

978-2-296-55533-4. 28 euros

Raymond Huard

\section{(2) OpenEdition}

Journals

Édition électronique

URL : http://journals.openedition.org/rh19/4515

DOI : $10.4000 /$ rh 19.4515

ISSN : $1777-5329$

Éditeur

La Société de 1848

Édition imprimée

Date de publication : 1 juin 2013

Pagination : 232-233

ISSN : 1265-1354

Référence électronique

Raymond Huard, «Claudine Hérody-Pierre, Robert Schnerb, un historien dans le siècle (1900-1962). Une vie autour d'une thèse », Revue d'histoire du XIXe siècle [En ligne], 46 | 2013, mis en ligne le 13 janvier 2014, consulté le 22 septembre 2020. URL : http://journals.openedition.org/rh19/4515 ; DOI : https:// doi.org/10.4000/rh19.4515

Ce document a été généré automatiquement le 22 septembre 2020

Tous droits réservés 


\section{Claudine Hérody-Pierre, Robert Schnerb, un historien dans le siècle (1900-1962). Une vie autour d'une thèse}

Collection Inter-National, Paris, L'Harmattan, 2011, 292 p. ISBN :

978-2-296-55533-4. 28 euros

\section{Raymond Huard}

\section{RÉFÉRENCE}

Claudine Hérody-Pierre, Robert Schnerb, un historien dans le siècle (1900-1962). Une vie autour d'une thèse, collection Inter-National, Paris, L'Harmattan, 2011, 292 p. ISBN :

978-2-296-55533-4. 28 euros

1 Robert Schnerb, qui avait débuté par une thèse sur la Révolution, fut aussi un éminent dix-neuviémiste, qui contribua d'ailleurs aux travaux de la Société d'histoire de la révolution de 1848. Beaucoup plus qu'un simple hommage à caractère familial, l'ouvrage que lui consacre sa petite-fille Claudine Hérody-Pierre, elle-même docteure en histoire, est une étude fort bien documentée, qui se garde de tomber dans l'hagiographie, et à travers le cas de cet historien, aide à percevoir la complexité de l'atmosphère universitaire et politique de son époque.

2 Né dans une famille de commerçants juifs originaires d'Alsace et résidant en Bourgogne, Robert Schnerb, qui a été circoncis et a fait sa barmitsvah, se range cependant parmi ces juifs parfaitement intégrés, non pratiquants, rationalistes et même anticléricaux, nombreux en France. Élève à Dijon de Lucien Febvre et de Gaston Roupnel, puis, à l'université, de l'orageux Albert Mathiez, agrégé en 1923, il est nommé à Clermont-Ferrand, et il dépose, sous la direction de Mathiez, un sujet de thèse sur un domaine encore très peu étudié, Les contributions directes à l'époque de la Révolution française dans le Puy-de-Dôme. Marié en 1928, contre le vœu de sa famille, à Madeleine Liebschütz, agrégée d'histoire, qui sera pour lui une compagne exemplaire, il s'enracine 
en Auvergne en achetant une belle propriété à Coudes, au sud de Clermont. Ces heureux débuts débouchent malheureusement sur une lourde déception. Mathiez meurt en 1932 et c'est Philippe Sagnac qui le remplace auprès de Robert Schnerb. Lors de la soutenance de la thèse en 1933, « soutenance étranglée » selon le mot de Philippe Sagnac, car on n'y discute guère du fond du travail, le jury où figurent - à côté de Philippe Sagnac et Olivier Bloch, favorables au candidat - Henri Hauser, CharlesHippolyte Pouthas et Marcel Marion, n'accorde à la thèse que la mention " honorable » et met ainsi un obstacle de taille à l'accession du nouveau docteur à l'université. Décision injuste, de toute évidence : l'absence de Mathiez, le caractère très neuf du sujet, la sous-estimation des recherches accomplies, le fait que Robert Schnerb soit encore peu connu des milieux universitaires parisiens et ne soit pas normalien, les critiques désobligeantes d'Henri Hauser ont contribué à faire apparaître l'auteur de la thèse plutôt comme un tâcheron, n'ayant pas l'étoffe d'un maître. Malgré le soutien de Georges Lefevbre et les efforts de Robert Schnerb pour compenser ce handicap par des travaux de qualité, notamment dans les Annales d'histoire économique et sociale, celui-ci se voit préférer jusqu'à la Seconde Guerre mondiale d'autres candidats pour un poste à Clermont. La nature de son engagement en politique a aussi pu contribuer à cet échec. En effet, anticlérical et plutôt antimilitariste, Robert Schnerb s'est rapproché des communistes pendant la guerre du Rif, mais c'est surtout la menace d'extrême droite qui le mobilise à partir de 1934. Il est secrétaire du Comité de vigilance antifasciste clermontois, soutient le Front populaire, avant de se ranger dans la frange pacifiste du Comité de vigilance des intellectuels antifascistes (C.V.I.A). Séduit par Bergery et Valois, il juge le Front populaire prisonnier du capitalisme et du communisme et sousestime gravement l'antisémitisme nazi. Comme beaucoup de Français, il reçoit avec soulagement les accords de Munich. En 1938, il est nommé à Sceaux, et s'investit tant à L'Information historique que dans la Société des professeurs d'histoire et géographie.

3 L'arrivée au pouvoir du régime de Vichy et les lois antijuives bouleversent complètement l'existence des Schnerb et de leurs deux enfants. "Repliés » à Clermont, Robert Schnerb et sa femme peuvent d'abord résider à Coudes, mais ils sont radiés de l'enseignement et doivent vivre d'une retraite incomplète. Bien plus, à partir de 1943, ils sont contraints à la clandestinité dans un gîte montagnard près de La Bourboule, moins affectés malgré tout qu'une grande partie de leur famille qui fut exterminée par les nazis. À la sortie de l'épreuve, Robert Schnerb tente à nouveau d'accéder à l'université, mais le fait qu'il ait été une victime plus qu'un résistant, et surtout le poids des manœuvres universitaires dont l'auteure donne une description assez pittoresque, l'en empêchent. L'homme, un "grand nerveux", assez raide, ne se montrait pas toujours très diplomate. Il devra se contenter d'un poste à la khâgne de Clermont où il laissera un grand souvenir. Dans cette fonction, il multiplie les activités dans les sociétés savantes (Société des études robespierristes et celle de 1848) et dans les revues (en particulier dans L'Information historique dont il sera rédacteur en chef), écrit deux de ses œuvres maîtresses, Rouher et le Second Empire et surtout le beau xixe siècle de la collection Histoire générale des civilisations dirigée par Maurice Crouzet ${ }^{1}$. Frayant avec des historiens influencés par le marxisme (Labrousse, Soboul, Lefebvre, Dommanget), se défiant de toute pensée conservatrice et atlantiste, il récuse toutefois l'engagement militant. Il disparaît à soixante ans en 1962. Claudine Hérody-Pierre, qui trace de l'homme un portrait nuancé, s'interroge pour finir sur le rôle de la judéité de Robert Schnerb dans les obstacles qu'il a pu rencontrer dans sa carrière, impact évidemment difficile à prouver et qui interfère avec d'autres déterminations. 


\section{NOTES}

1. Robert Schnerb, Rouher et le Second Empire, Paris, Armand Colin, 1949 ; Robert Schnerb, Le XIX ${ }^{\mathrm{e}}$ siècle, l'apogée de l'expansion européenne, 1815-1914, collection Histoire générale des civilisations (tome 6), Paris, Presses universitaires de France, 1955. 